\title{
Mechanical properties of ultra-fine grained zirconia ceramics
}

\author{
G. S. A. M. THEUNISSEN, J. S. BOUMA*, A. J. A. WINNUBST ${ }^{\ddagger}$, \\ A. J. BURGGRAAF \\ Faculty of Chemical Technology, Laboratory for Inorganic Chemistry, Materials Science and \\ Catalysis, University of Twente, PO Box 217, 7500 AE Enschede, The Netherlands
}

The mechanical properties of tetragonal zirconia (TZP) materials doped with $Y, C e$ or Ti were studied as a function of temperature and grain size. Fine grained $Y-T Z P$ (grain size $<0.3 \mu \mathrm{m}$ ) shows values for fracture toughness and strength at room temperature, which are comparable with the coarse grained transformation toughened materials, despite lacking transformation toughening. The morphology of the fracture surface points to crack deflection as the most important toughening mechanism. At $800^{\circ} \mathrm{C}$ fracture toughness and strength are higher than in coarse grained Y-TZP materials. Doping Y-TZP with $\mathrm{Ce}$ or Ti results in a similar trend in mechanical properties, for fine grained material, as for the $Y$-TZP materials.

\section{Introduction}

Poly-crystalline $100 \%$ tetragonal $\mathrm{ZrO}_{2}-\mathrm{Y}_{2} \mathrm{O}_{3}$ ceramics (Y-TZP) are regarded as materials exhibiting high strength and toughness. In order to obtain a fully stabilized tetragonal structure at room temperature, the ceramic grain size must be less than $0.8 \mu \mathrm{m}$ in the case of a $3 \mathrm{~mol} \% \mathrm{Y}_{2} \mathrm{O}_{3}$ doped tetragonal $\mathrm{ZrO}_{2}$ ceramic [1].

In the literature a large variety of fracture toughness values are reported $[2-8]$. These values vary typically between 4-19 $\mathrm{MPam}^{-1 / 2}$. Comparison of these values is difficult because of the different measuring techniques applied (e.g. indentation, bending tests), grain sizes, densities and impurity levels of the materials. In general, however, the higher values are obtained from $100 \%$ dense samples with relatively large grain sizes (but smaller than the critical grain size). To obtain the theoretical density, hot isostatic pressing (HIP), hot press or high temperature treatments are necessary. Although the mechanical properties of these materials might be good at room temperature, a strong decrease is expected at elevated temperatures. Besides this, the coarser grained materials are not very resistant to thermal and chemical ageing $[9,10]$.

In zirconia ceramics the stress induced phase transformation from the tetragonal to the monoclinic phase is considered to be the main toughening mechanism [11]. In order to obtain high values for bending strength and fracture toughness in these materials, the contribution of transformation toughening should be maximized. Lange [12] and McMeeking and Evans [13] derived equations for the toughness increment due to stress induced phase transformation. The equation derived by McMeeking [13] is

$$
K_{\mathrm{lc}}=K_{\mathrm{lc}}^{\mathrm{m}}+\frac{\eta V_{\mathrm{f}} \Delta V E(h)^{1 / 2}}{1-v}
$$

where $K_{\mathrm{Ic}}$ and $K_{\mathrm{Ic}}^{\mathrm{m}}$ are the actual fracture toughness and the fracture toughness of the matrix without transformation toughening, respectively, $\eta$ is a constant, $V_{\mathrm{f}}$ is the fraction transformed tetragonal phase, $\Delta V$ is the volume expansion (due to the transformation), $E$ is the Young's modulus, $h$ is the half width of the transformation zone and $v$ is the Poisson constant. In a certain material only $V_{\mathrm{f}}$ and $h$ are not constant and should be optimized (i.e. a large transformation zone and a large fraction transformable phase). Such a ceramic might be obtained in two ways: (i) directly firing to the appropriate grain size and (ii) after forming of the material in the ultra-fine grained state a heat treatment is given in order to increase the grain size to the appropriate level (TTT-procedure).

As shown by a number of authors the width of the transformation zone decreases with an increase in test temperature and a decrease in grain size $[3,8,14,15]$. Tsukuma and Ueda [2] showed that, when the size of the transformation zone is large, a value as high as $1400 \mathrm{MPa}$ is obtained for the bending strength and $20 \mathrm{MPa} \mathrm{m}^{-1 / 2}$ for the fracture toughness (for $2 \mathrm{~mol} \%$ $\mathrm{Y}_{2} \mathrm{O}_{3}$ doped $\mathrm{ZrO}_{2}$ ). In these cases the contribution of stress induced phase transformation is about 15-20 $\mathrm{MPa} \mathrm{m}^{-1 / 2}$.

It is assumed that when the grain size is smaller than approximately $0.4 \mu \mathrm{m}$ no stress induced phase transformation occurs [7]. Due to the lack of this toughening mechanism, lower strength and fracture toughness are generally expected at room temperature. However, the material might become interesting

\footnotetext{
* Present address: BASF Nederland BV, Arnhem, The Netherlands.

${ }^{\star}$ Author to whom all correspondence should be sent.
} 
again when the grain size reaches the dimensions of those of the domains $(50 \mathrm{~nm})$ in tetragonal zirconia single crystals and toughening by a crack deflection mechanism becomes possible $[16,17]$. It is our expectation that when crack deflection is operative as a toughening mechanism in materials with very small grain size, even at elevated temperatures a relatively high fracture toughness can be expected. Initial experiments performed by Bouma et al. [18] on fine grained Y-TZP indeed show a more gradual decrease in fracture toughness with temperature compared to coarser grained material. Finally these materials are also more resistant to chemical and thermal ageing $[9$, 10, 19].

Another way to improve the strength and toughness in combination with improved resistance against chemical and thermal ageing is the use of other dopants like $\mathrm{Ce}$ or Ti. Tsukuma [14] reported a $K_{\mathrm{Ic}}$-value as high as $35 \mathrm{MPa} \mathrm{m}^{-1 / 2}$ for a tetragonal zirconia ceramic doped with $12 \mathrm{~mol} \% \mathrm{CeO}_{2}$. A disadvantage however is that, in general $\mathrm{Ce}-\mathrm{TZP}$ is more difficult to densify, which usually results in lower densities and larger grain sizes. As small grain sizes can be obtained in Y-TZP ceramics [20] the positive effects of yttrium and cerium might be combined. Recent work on $\mathbf{Y}, \mathrm{Ce}-\mathrm{TZP}$ ceramics $[21,22]$ indeed show that good mechanical properties are obtained in $\mathrm{Y}, \mathrm{Ce}-\mathrm{TZP}$ ceramics, especially when the cerium concentration is low [23].

In this paper the results of bending strength and fracture toughness experiments on pressureless sintered (ultra) fine grained $\mathrm{Y}, \mathrm{Ce}$ and $\mathrm{Ti}$ doped zirconia ceramics are presented. The mechanical properties are measured as a function of temperature and grain size. If possible, $K_{\mathrm{Ic}}$ values are correlated with the width of the transformation zone.

Some preliminary experiments were performed on samples which were submitted to a post-HIP treatment.

\section{Experimental procedure}

Ultra-fine grained $\mathrm{ZrO}_{2}$ powders doped with $\mathrm{Y}, \mathrm{Ce}$ and $\mathrm{Ti}$ were prepared by hydrolysis of a mixed $\mathrm{ZrCl}_{4}-\mathrm{YCl}_{3}$ solution in ammonia [24]. The compositions investigated are listed in Table I.

The powders were cold isostatically pressed at $400 \mathrm{MPa}$. The green compacts were sintered in a Vecstar tube furnace at temperatures between 1150 and $1600^{\circ} \mathrm{C}$ to obtain ceramics with different grain sizes. From commercial Tosoh powders (see Table I) bars were uniaxially pressed at $100 \mathrm{MPa}$ followed by cold isostatic pressing at $400 \mathrm{MPa}$ and sintering at $1550^{\circ} \mathrm{C}$ for $2 \mathrm{~h}$.

Some Y-TZP samples, sintered at $1150^{\circ} \mathrm{C}$ for $10 \mathrm{~h}$ $\left(\rho_{\text {rel }}=97 \%\right)$, were post-HIPped at $1100^{\circ} \mathrm{C}$ for $1 \mathrm{~h}$ under a pressure of $100 \mathrm{MPa}$ in an $\mathrm{Ar}$ atmosphere.

The bulk densities of the sintered samples were measured using the Archimedes technique in mercury.

Scanning electron microscopy (SEM) pictures were made from external and fracture surfaces on a Hitachi S-800 and Jeol JSM-35CF scanning electron microscope. Grain sizes were determined using the method of Oel [25] taking more than 300 grains for each measurement.

The samples were cut into bars of $30 \times 5 \times 2 \mathrm{~mm}^{3}$ to measure bending strength. These samples were polished single-sided with $0.3 \mu \mathrm{m}$ diamond paste, cleaned ultrasonically in ethanol and annealed at $700{ }^{\circ} \mathrm{C}$ with heating and cooling rates of $1{ }^{\circ} \mathrm{C} \mathrm{min}^{-1}$ in order to remove stresses introduced by machining. The strength measurements by four-point bending were performed using a test configuration with an inner and outer span of 10 and $20 \mathrm{~mm}$, respectively. A crosshead speed of $0.7 \mathrm{~mm} \mathrm{~min}^{-1}$ was used in all cases.

The bending strength, $\sigma_{\mathrm{f}}$, is calculated with the standard formula

$$
\sigma_{\mathrm{f}}=\frac{3 P L}{b^{2} w}
$$

where $L$ is half the difference between inner and outer span, $P$ the load at fracture and $b$ and $w$ the sample width and height, respectively. The bending strength data are assumed to follow the Weibull probability function [26]

$$
P(\sigma)=1-\exp \left(-\left[\frac{\sigma}{\sigma_{0}}\right]^{m} V\right)
$$

where $P(\sigma)$ is the probability of failure at or below a stress $\sigma, m$ is the Weibull modulus, $V$ the sample volume and $\sigma_{0}$ a scale parameter with the same dimensions as $\sigma$. All samples are assumed to have the same volume and stress distribution. The estimator

$$
\mathbf{P}_{j}=\frac{2 j-1}{2 n}
$$

was used in all cases [26]. In this equation $j$ represents the $j$ th result in the total set of $n$ samples. The slope in the Weibull plot (logarithm of probability versus logarithm of strength) is the Weibull modulus, $m$.

The fracture toughness is measured by the threepoint single-edge notched beam technique (SENB), using a test configuration with a span of $12 \mathrm{~mm}$. For this, bars with the dimensions $15 \times 3 \times 1 \mathrm{~mm}^{3}$, a notch length of $500 \mu \mathrm{m}$ and a notch width of $60 \mu \mathrm{m}$ were cut. These specimens were not pre-cracked. A crosshead speed of $0.3 \mathrm{~mm} \mathrm{~min}^{-1}$ was used in all cases. Room temperature fracture toughness measurements were

\begin{tabular}{|c|c|c|c|c|}
\hline Code & $\begin{array}{l}\mathrm{mol} \% \\
\mathrm{ZrO}_{2}\end{array}$ & $\begin{array}{l}\mathrm{mol} \% \\
\mathrm{YO}_{1.5}\end{array}$ & $\begin{array}{l}\mathrm{mol} \% \\
\mathrm{CeO}_{2}\end{array}$ & $\begin{array}{l}\mathrm{mol}^{\circ} \% \\
\mathrm{TiO}_{2}\end{array}$ \\
\hline $\mathrm{TZ}-2 \mathrm{Y}^{\mathrm{a}}$ & 97.1 & 3.9 & - & - \\
\hline$T Z-3 Y^{a}$ & 94.2 & 5.8 & - & - \\
\hline$T Z-3 Y^{a} B^{a}$ & 94.2 & $5.8+$ binder & - & - \\
\hline ZY5 & 95 & 5 & - & - \\
\hline ZY5.8 & 94.2 & 5.8 & - & - \\
\hline $\mathrm{ZCe} 12$ & 90 & - & 12 & - \\
\hline ZY4Ce10 & 86 & 4 & 10 & - \\
\hline ZY4Ce2 & 94 & 4 & 2 & - \\
\hline ZY5Ti5 & 90 & 5 & - & 5 \\
\hline
\end{tabular}
carried out on samples which were dried at $120^{\circ} \mathrm{C}$ for

TABLE I Compositions of the samples used in this study

${ }^{\text {a }}$ Commercially available powders (Tosoh Manufacturing Co. Ltd, Tokyo, Japan) 
$2 \mathrm{~h}$ and then stored in a desiccator to avoid adsorption of water.

The fracture toughness, $K_{\mathrm{Ic}}$, is calculated from [27]

$$
K_{\mathrm{Ic}}=\frac{3 P \operatorname{sy}(a)^{1 / 2}}{2 b w^{2}}
$$

with $s$ the span width, $a$ the crack length, $y$ a correction factor and the other parameters as stated before.

The temperature dependence of bending strength and fracture toughness was measured at temperatures of approximately $20,320,500$ and $750^{\circ} \mathrm{C}$. The high temperature measurements were performed after an equilibration period of $0.5-1 \mathrm{~h}$ at a fixed temperature. For each data point, 6 to 9 samples were measured.

$X$-ray diffraction (XRD) measurements were performed to study the phase composition of the fracture and external surfaces using a Philips PW1710 diffractometer with $\mathrm{Cu} K_{\alpha}$ radiation. The unit cell parameters of the tetragonal phase were calculated from powders heat treated at $1400^{\circ} \mathrm{C}$ with $\mathrm{Si}$ as an internal standard. When a significant amount of monoclinic phase was found at the fracture surface the exact phase composition and width of the transformation zone was determined using Raman spectroscopy.

The Raman measurements were performed in a way as shown in Fig. 1 with a SPEX $18770.6 \mathrm{~m}$ triple spectrometer using a $25 \mathrm{~mW}$ laser with a wavelength of $534 \mathrm{~nm}$ and a spot size of about $1.0 \mu \mathrm{m}$. Over the range $100-300 \mathrm{~cm}^{-1}$ the monoclinic (at 181 and $192 \mathrm{~cm}^{-1}$ ) and tetragonal bands (at 105 and $224 \mathrm{~cm}^{-1}$ ) of the tetragonal and monoclinic zirconia polymorphs, respectively, are well separated $[28,29]$. The fraction monoclinic phase, $f_{\mathrm{m}}$, is expressed by [30]

$$
f_{\mathrm{m}}=\frac{I_{\mathrm{m}}^{181}+I_{\mathrm{m}}^{192}}{F\left(I_{\mathrm{t}}^{148}+I_{\mathrm{t}}^{264}\right)+\left(I_{\mathrm{m}}^{181}+I_{\mathrm{m}}^{192}\right)}
$$

where $I$ is the intensity of the Raman peak after background correction (dotted line in Fig. 2), $\mathrm{m}$ and $\mathrm{t}$ the monoclinic and tetragonal phase, respectively, and the numeric values the Raman shift in $\mathrm{cm}^{-1}$. The correction factor, $F$, is assumed to be close to unity [30]. The half width of the transformation zone is determined as the width where the fraction monoclinic phase has decreased to $1 / e$ of the fraction monoclinic phase at the fracture surface [3].

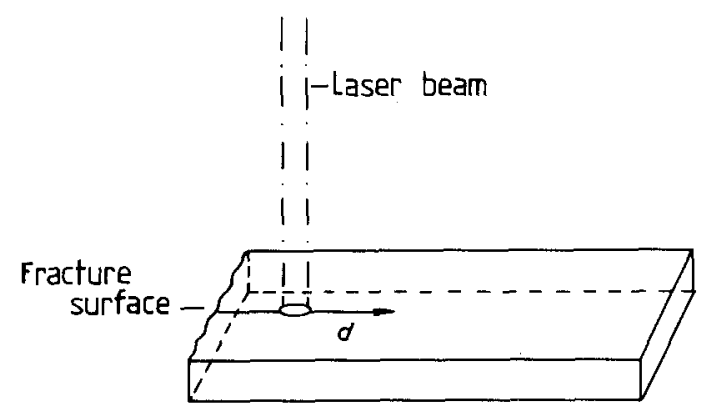

Figure I Set-up during the Raman measurements. The phase composition is determined as a function of the distance, $d$, from the fracture surface.

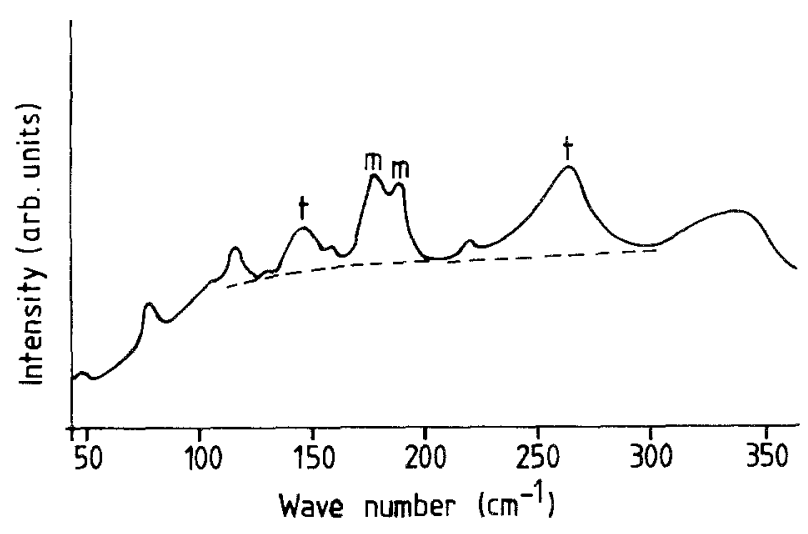

Figure 2 Raman spectrum of a TZ-2Y sample with about 60 vol $\%$ monoclinic phase and 40 vol \% tetragonal phase. The dotted line represents the background.

TABLE II Relative densities and grain sizes of samples used

\begin{tabular}{lcccc}
\hline Sample & $\begin{array}{l}\text { Rel. density } \\
(\%)\end{array}$ & $\begin{array}{l}\text { Grain size } \\
(\mu \mathrm{m})\end{array}$ & $\begin{array}{l}T_{\text {sinter }} \\
\left({ }^{\circ} \mathrm{C}\right)\end{array}$ & $\begin{array}{l}\text { Time } \\
(\mathrm{h})\end{array}$ \\
\hline ZY4 & 97 & 0.15 & 1117 & 70 \\
ZY5 & 97 & 0.18 & 1150 & 10 \\
ZY5 & $>99$ & 0.30 & 1400 & 2 \\
ZY5 & 98 & $\sim 0.75$ & 1600 & 2 \\
ZY6 & 98 & 0.20 & 1180 & 16 \\
TZ-2Y & $>99$ & 0.70 & 1550 & 3 \\
TZ-3Y & $>99$ & 0.70 & 1550 & 3 \\
TZ3YB & $>99$ & 0.60 & 1600 & 2 \\
ZY4Ce2 & 99 & $\sim 0.14$ & 1150 & 10 \\
ZCe12 & 98 & 0.25 & 1200 & 10 \\
ZY5Ti5 & 98 & 0.20 & 1100 & 10 \\
\hline
\end{tabular}

\section{Results and discussion}

The relative densities and grain sizes obtained are shown in Table II. From this table it is seen that all the Tosoh samples are nearly $100 \%$ dense while this is not the case for all the synthesized powders. SEM pictures of the microstructure of ZY5 samples with an average grain size of 0.18 and $0.30 \mu \mathrm{m}$ are shown in Figs 3 and 4 , respectively. XRD measurements showed that after sintering all the samples were $100 \%$ tetragonal. After cutting, the surfaces contained about $7 \%$ monoclinic phase which disappeared after polishing and annealing.

\subsection{Y-TZP}

Bending strength as a function of the temperature is given for the Y-TZP samples in Fig. 5. As seen in this figure, the bending strength remains relatively constant up to about $300^{\circ} \mathrm{C}$ (the highest value for the TZ3YB compact). At higher temperatures a strong decrease is observed in the samples with an average grain size of 0.3 and $0.6 \mu \mathrm{m}$ while the bending strength in the sample with an average grain size of $0.18 \mu \mathrm{m}$ decreases only gradually. It is interesting to note that above $750^{\circ} \mathrm{C}$ the bending strength of the $0.18 \mu \mathrm{m}$ material is higher compared with the other samples.

For the $0.18 \mu \mathrm{m}$ Y-TZP, the Weibull modulus decreases from 16 to 4 with increasing temperature 


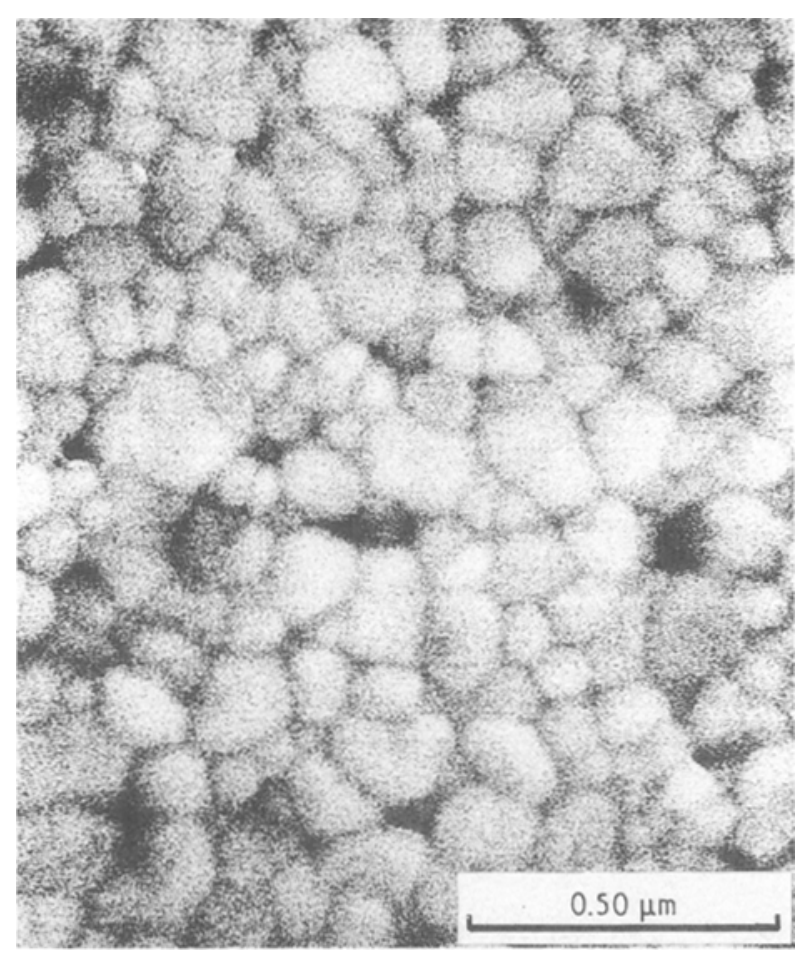

Figure 3 SEM picture of ZY5 with a mean grain size of $0.18 \mu \mathrm{m}$.

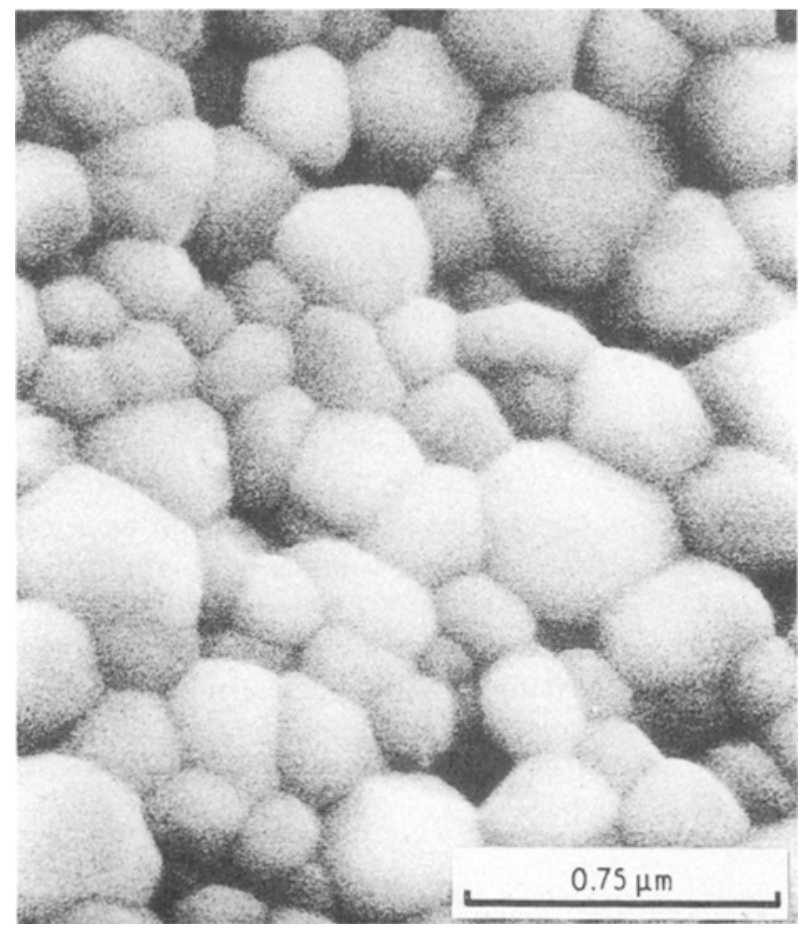

Figure 4 SEM picture of ZY5 with a mean grain size of $0.37 \mu \mathrm{m}$.

(Fig. 5), while for the $0.30 \mu \mathrm{m}$ and TZ3YB material a reverse tendency is observed (from 4 to 14 and 9 to 13 , respectively). It seems that the coarser grained $100 \%$ dense materials have a higher reliability at high temperature, in contrast to the smaller grained and less dense ceramics, which are more reliable at room temperature. Presumably the pores present give rise to formation of cracks which are more active at higher temperatures. Therefore these must be eliminated.

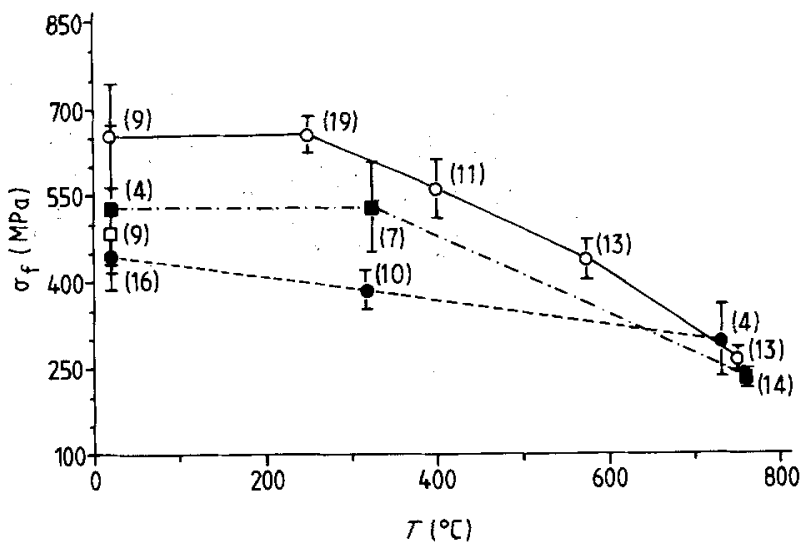

Figure 5 Bending strength as a function of temperature for various grain sizes. The numbers in the parenthesis represent the Weibull modulus: (O) TZ3YB, $0.6 \mu \mathrm{m}$; (•) ZY5, $0.18 \mu \mathrm{m}$; (ロ) ZY5, $0.30 \mu \mathrm{m}$; ( $\square$ ) ZY5, $0.75 \mu \mathrm{m}$.

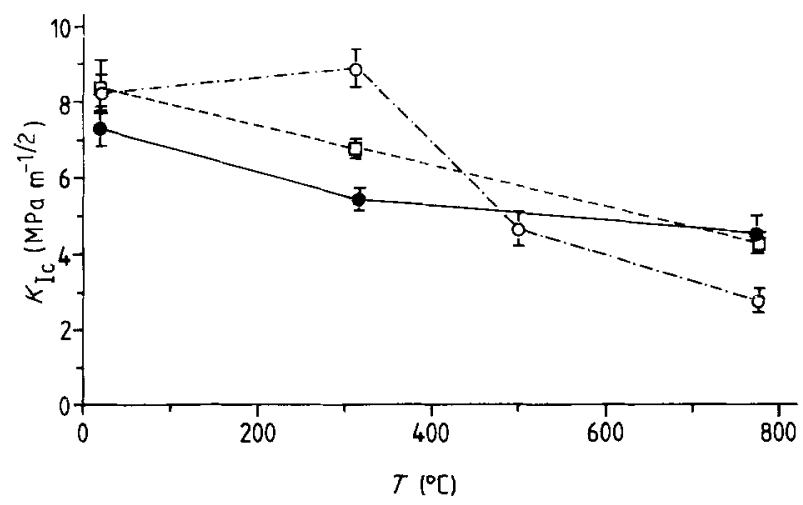

Figure 6 Fracture toughness of $\mathrm{ZY5}$ with various grain sizes as a function of temperature: $(\bullet) 0.18$; ( $\square) 0.30$ and $(\bigcirc) 0.75 \mu \mathrm{m}$.

TABLE III Values for the fraction transformed tetragonal zirconia, the width of the transformation zone and the fracture toughness of zirconia materials fractured at various temperatures

\begin{tabular}{lrlcl}
\hline Sample & $T_{\mathrm{f}}\left({ }^{\circ} \mathrm{C}\right)$ & $V_{\mathrm{f}}$ & $h(\mu \mathrm{m})$ & $\begin{array}{l}K_{\mathrm{Ic}} \\
\left(\mathrm{MPa} \mathrm{m}^{-1 / 2}\right)\end{array}$ \\
\hline TZ-2Ya & 20 & 60 & 30 & 14 \\
TZ-3Y & 20 & 20 & 10 & 10 \\
ZY4 & 20 & - & 0 & 10 \\
ZY6 & 20 & - & 0 & 9 \\
ZY5 $(0.18 \mu \mathrm{m})$ & 20 & - & 0 & 7.3 \\
ZY5 $(0.18 \mu \mathrm{m})$ & 317 & - & 0 & 5.5 \\
ZY5 $(0.18 \mu \mathrm{m})$ & 773 & - & 0 & 4.5 \\
ZY5 $(0.3 \mu \mathrm{m})$ & 20 & - & 0 & 8.4 \\
ZY5 $(0.3 \mu \mathrm{m})$ & 313 & - & 0 & 6.8 \\
ZY5 $(0.3 \mu \mathrm{m})$ & 760 & - & 0 & 4.3 \\
ZY5 $(0.75 \mu \mathrm{m})$ & 20 & 45 & 20 & 8.3 \\
ZY5 $(0.75 \mu \mathrm{m})$ & 300 & 54 & 30 & 8.7 \\
ZY5 $(0.75 \mu \mathrm{m})$ & 500 & 10 & 5 & 4.8 \\
ZY5 $(0.75 \mu \mathrm{m})$ & 775 & - & 0 & 2.8 \\
\hline
\end{tabular}

${ }^{\mathrm{a}} K_{\mathrm{Ic}}$ measured by indentation

In Fig. 6 values for the fracture toughness are given for the Y-TZP samples as a function of the temperature. In Table III the half widths of the transformation zones are listed in combination with fracture toughness data of some other Y-TZP samples. In accordance with Equation 1 the samples with 
a large size of the transformation zone show a good fracture toughness at room temperature (Table III). As expected the fracture toughness decreases with increasing temperature (Fig. 6). However the decrease in the 0.18 and $0.30 \mu \mathrm{m}$ materials is less compared with that of the $0.75 \mu \mathrm{m}$ material. Especially above $300^{\circ} \mathrm{C}$ the decrease in fracture toughness of the $0.75 \mu \mathrm{m}$ material is rather drastic. This can be attributed to a decrease in size of the transformation zone and degree of transformation (Table III) and thus, according to Equation 1, to a decrease in fracture toughness. A decrease in size of the transformation zone could be expected because at a temperature of about $500^{\circ} \mathrm{C}$ the tetragonal phase becomes stable (and hence more difficult to transform). This leads, at $750^{\circ} \mathrm{C}$, to a fracture toughness of about 2-3 $\mathrm{MPa} \mathrm{m}^{-1 / 2}$ which is comparable with the fracture toughness in cubic materials as reported by Winnubst et al. [31] and Ingel et al. [17].

Based on Equation 1 values of $V_{\mathrm{f}}(h)^{1 / 2}$ can be calculated. Using the $K_{\mathrm{Ic}}$ data of Table III and the parameter data of Wang et al. [8] (i.e. $\eta=0.23, \Delta V$ $=0.05, \quad E=220 \mathrm{GPa} \quad$ and $\quad v=0.31, \quad K_{\mathrm{Ic}}^{\mathrm{m}}$ $\left.=3 \mathrm{MPa} \mathrm{m}^{-1 / 2}\right)$ a value of $3 \mu \mathrm{m}^{1 / 2}$ is calculated for the TZ-2Y sample. The value of $V_{\mathrm{f}}(h)^{1 / 2}$ can also be calculated directly from measurements of $V_{\mathrm{f}}$ and $(h)^{1 / 2}$. Using Equation 6 the fraction monoclinic phase is calculated from a typical Raman spectrum as shown in Fig. 2. The Raman profile of this sample is shown in Fig. 7. At the fracture surface the percentage monoclinic phase is about $60 \%$. From Fig. 7 the size of the transformation zone is estimated to be about $30 \mu \mathrm{m}$ (see also Table III). Using $V_{\mathrm{f}}=0.6$ and $h=30 \mu \mathrm{m}$, $V_{\mathrm{f}}(h)^{1 / 2}$ equals $3.3 \mu \mathrm{m}^{1 / 2}$. This is in good agreement with the calculated value. The values for $V_{\mathrm{f}}(h)^{1 / 2}$ as reported by Wang et al. [8] and Masaki and Sinjo [3] are lower $\left(\sim 1.5-2 \mu \mathrm{m}^{1 / 2}\right)$. This may be due to the fact that they measured zone sizes by means of XRD while our zone sizes are obtained by Raman spectroscopy.

Although the fracture toughness of the finer grained materials (i.e. 0.18 and $0.30 \mu \mathrm{m}$ ) is slightly lower at low temperature compared with the coarser grained materials they are relatively high. This is especially the case considering the fact that the size of the transformation zone is minimal (i.e. no monoclinic phase at the fracture surface (Table III)). Recently, a number of papers has been devoted to ferroelastic domain switching as a toughening mechanism $[32,33]$. This involves the stress-induced alignment of the $c$-axis of the tetragonal phase along the maximum principal stress axis which results in a shape change of a pure shear type. Evidence of domain switching is usually offered with XRD. However we did not find a preferential alignment of the $c$-axis normal to the surface, as is in agreement with the results of $\mathrm{Li}$ et al. [34] and Reidinger and Whalen [35]. Hence domain switching as a toughening mechanism does not seem very likely for these materials.

At room temperature Michel et al. [16] and Ingel et al. [17] found values of 6 and $9 \mathrm{MPa} \mathrm{m}^{-1 / 2}$ for a $6 \mathrm{~mol} \% \mathrm{YO}_{1.5}$ doped zirconia single crystalline material, respectively, (the single crystals of Ingel contained a small fraction cubic phase). At $1000^{\circ} \mathrm{C}$

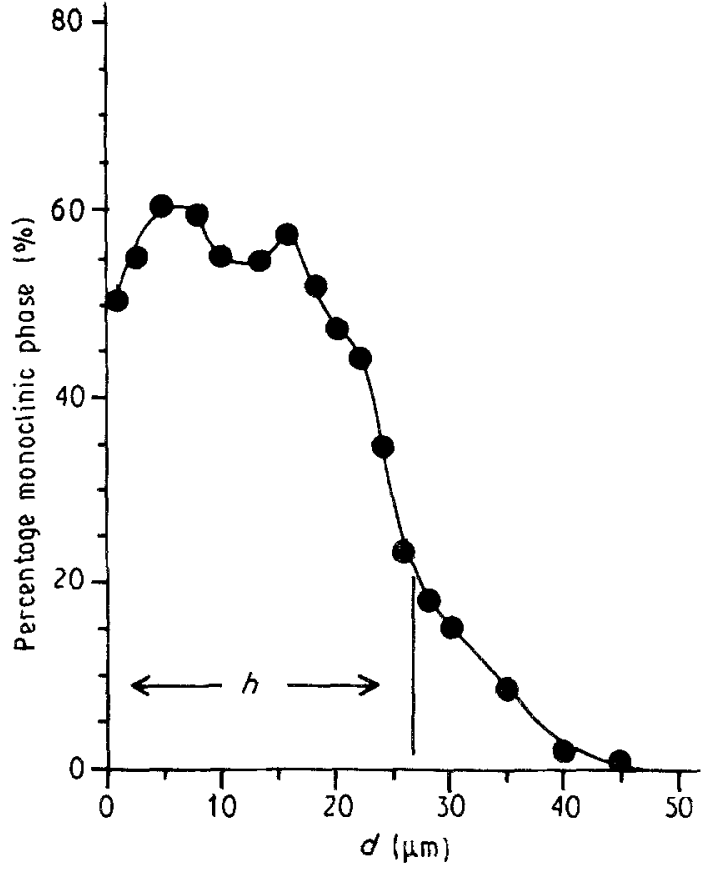

Figure 7 Phase composition of a TZ--2Y sample as a function of the distance $(d)$ from the fracture surface.

Ingel et al. [17] still found a value of $6 \mathrm{MPa} \mathrm{m}^{-1 / 2}$ which is clearly above the fracture toughness of cubic zirconia $\left(2 \mathrm{MPa} \mathrm{m}^{-1 / 2}\right)$. In all cases no monoclinic phase was found at the fracture surface suggesting the presence of another toughening mechanism than stress induced transformation toughening. Both $\mathrm{Mi}-$ chel et al. [16] and Ingel et al. [17] correlated the extremely rough surfaces and high fracture toughness of these materials with interaction of the crack with the multi-variant domain structure. The toughening increment would then vary between about 3-6 $\mathrm{MPa} \mathrm{m}^{-1 / 2}$. This is in agreement with results of Faber and Evans [36] and Heussner and Claussen [37] who found similar toughening increments in $\mathrm{Si}_{3} \mathrm{~N}_{4}$ and $\mathrm{Al}_{2} \mathrm{O}_{3}$ reinforced $\mathrm{Y}-\mathrm{TZP}$, respectively, where crack deflection was believed to be the (main) toughening mechanism. In Figs 8-11 the fracture surfaces of the 0.18 and $0.3 \mu \mathrm{m}$ specimen fractured at 20 and $730^{\circ} \mathrm{C}$ are shown. All the fracture surfaces are rather rough and contain a considerable fraction of intergranular fracture, which seems to increase slightly with temperature in both samples. According to Faber and Evans [38] crack deflection is a mechanism which can occur in multi-phase systems or in ceramics with low resistance interfaces. In single crystals a domain boundary can be a low resistance interface whereas the same applies for a grain boundary in poly-crystalline material. So a crack deflection mechanism can also occur in fine grained materials, where the small grains act as a sort of domain. Smaller grain sizes would result in a higher number of grain boundaries per unit length and thus in a larger possibility of crack deflection. Because of the fact that every deflection consumes energy, a higher number of deflections results in a higher fracture toughness. Based on some observations on coarse grained materials Faber and Evans [38] suppose that the crack deflection process 


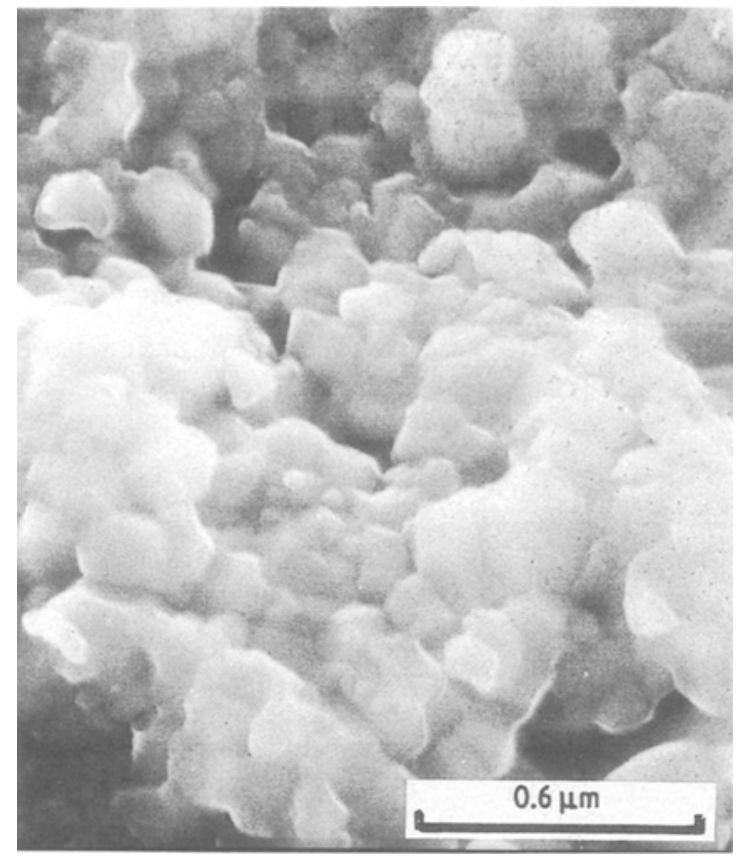

Figure 8 Fracture surface of $\mathrm{ZY} 5(0.18 \mu \mathrm{m})$ fractured at $20^{\circ} \mathrm{C}$.

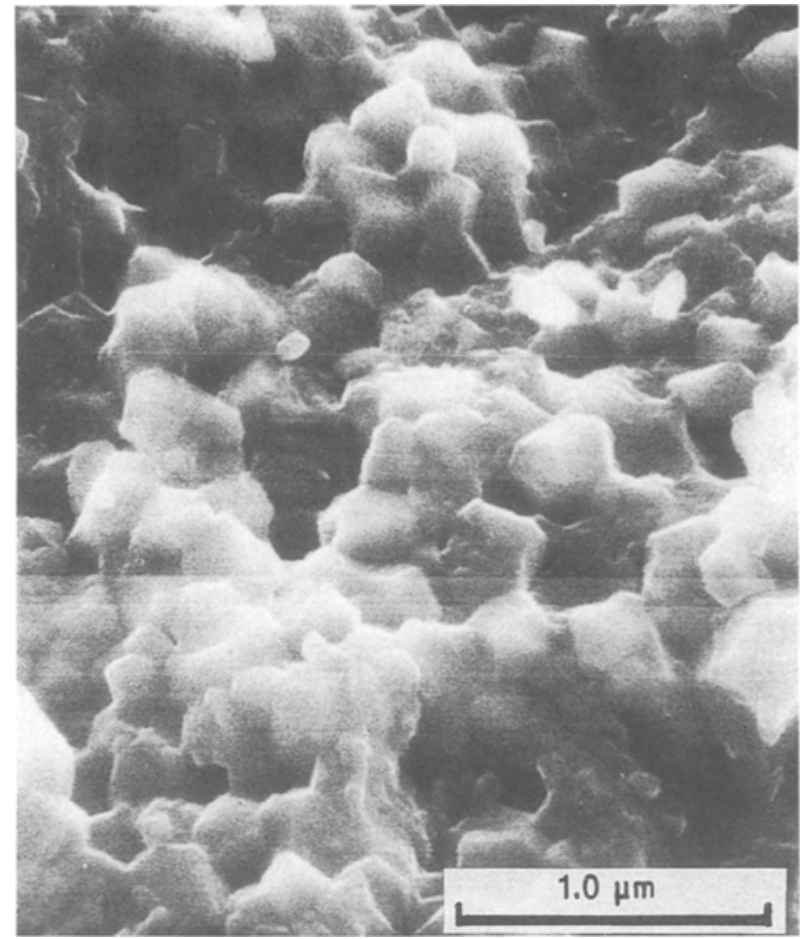

Figure 10 Fracture surface of $\mathrm{ZY} 5(0.30 \mu \mathrm{m})$, fractured at $20^{\circ} \mathrm{C}$.

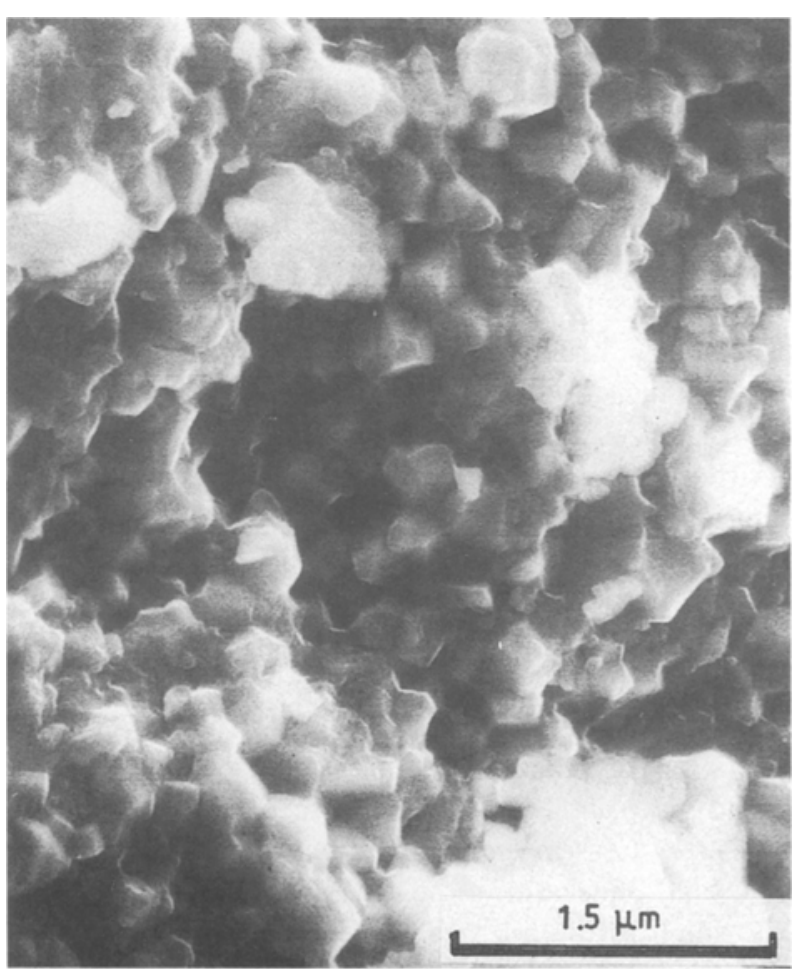

Figure 11 Fracture surface of $\mathrm{ZY} 5(0.30 \mu \mathrm{m})$, fractured at $760^{\circ} \mathrm{C}$.

coarse grained materials. Experiments with ceramics with grain sizes $\leqslant 0.1 \mu \mathrm{m}$ and high densities are in progress now.

From the previous discussion it could be expected that the $0.18 \mu \mathrm{m}$ material exhibited a higher bending strength and fracture toughness than the $0.30 \mu \mathrm{m}$ material. That this was not the case might be attributed to the lower density of the $0.18 \mu \mathrm{m}$ material. 
This has also been shown by Druschitz and Schroth [4] who found an increasing bending strength with decreasing porosity. Therefore it can be expected that the bending strength might be considerably improved when dense specimens are used, which means that fine grained Y-TZP ceramics potentially possess a good high temperature bending strength.

The decrease in fracture toughness (due to porosity) can be calculated from

$$
\gamma_{\mathrm{f}}=\gamma_{\mathrm{d}} \exp (-b p)
$$

and

$$
K_{\mathrm{Ic}}=\left(2 E \gamma_{\mathrm{f}}\right)^{1 / 2}
$$

where $\gamma_{f}$ and $\gamma_{d}$ represent the fracture energy for the porous and the dense system, respectively, $p$ the porosity, $E$ Young's modulus and $b$ a constant. With $b=2-5$, it can be calculated that $3 \%$ porosity lowers the fracture toughness approximately $5-14 \%$. However, the observed differences are somewhat larger which suggests that other effects, like a relatively large critical flaw size in the $0.18 \mu \mathrm{m}$ material, may also play a role.

When the critical flaw size, $c$, is independent of the grain size, $c$ can be calculated using Griffith's equation

$$
\sigma_{\mathrm{f}}=\frac{K_{\mathrm{lc}}}{(2 \pi c)^{1 / 2}}
$$

In case of Y-TZP $(0.30 \mu \mathrm{m})$, the critical flaw size is calculated to be about $30-40 \mu \mathrm{m}$ when fractured at room temperature, which compares well with the SEM picture shown in Fig. 12, where the crack initiating flaw is of that size. As agglomerates of this size occur in these powders [40] it seems reasonable to suggest that these flaws are remnants of fast densification of a few agglomerates which did not fracture

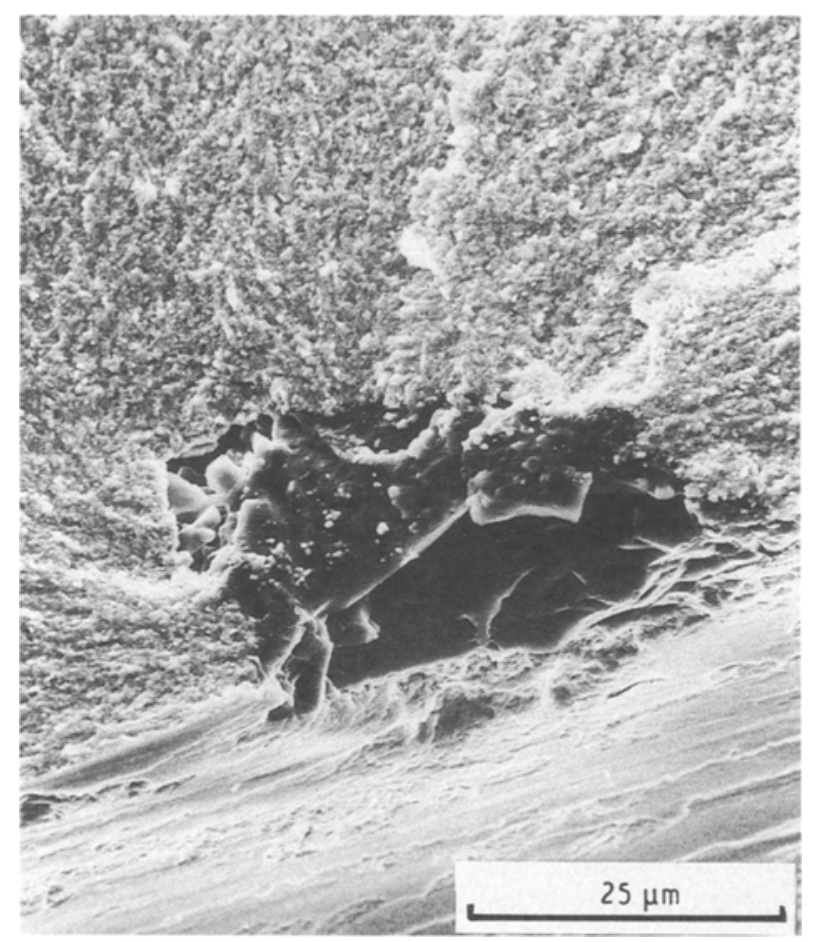

Figure 12 Fracture surface of a ZY5 sample (grain size $0.30 \mu \mathrm{m}$ ) showing a crack initiating flaw with a size of about $30 \mu \mathrm{m}$. during compaction. Experiments to improve the agglomerate structure are described in Reference 40 and experiments to remove the above mentioned flaws by HIP are described.

\section{2. $\mathrm{Ce}-\mathrm{TZP}, \mathrm{Y}, \mathrm{Ce}-\mathrm{TZP}$ and $\mathrm{Y}, \mathrm{Ti}-\mathrm{TZP}$}

Fracture toughness and bending strength data for the Y,Ce-TZP, Ce-TZP and Y,Ti-TZP samples are presented in Table IV. The bending strength values for $\mathrm{ZY} 4 \mathrm{Ce} 2$ and $\mathrm{ZY} 5 \mathrm{Ti} 5$ at room temperature are rather good compared to ZY5 whereas the bending strength of the $\mathrm{ZCe} 12$ sample is low. The low bending strength for Ce-TZP materials is a phenomenon which is frequently reported in literature. With increasing temperature, the strength of the ZY4Ce2 sample drops to a value which is comparable with the ZY5 samples. The ZY5Ti5 sample however, still shows a relatively good bending strength.

The values of the fracture toughness at room temperature are lower for all three samples than of ZY5. Considering the actual grain size of these ceramics and the critical grain size for transformation [41] it can be expected that there is hardly any contribution from transformation toughening to the total toughness. Nevertheless the fracture toughness is still relatively high. Therefore it is reasonable to suggest that in this case, a similar mechanism as in the Y-TZP ceramics might apply also.

Compared to the extreme high fracture toughness of the Ce-TZP materials reported in literature [14] (for materials with higher $\mathrm{Ce}$ concentration) our values are relatively low and therefore the high values need further examination. Tsukuma [14] measured a fracture toughness of $35 \mathrm{MPam}^{-1 / 2}$ (with microindentation) which cannot be explained by the small size of the transformation zone $(10 \mu \mathrm{m})$. Rose and Swain [42] reported, for a ZCe12 sample a typical zone width of $40 \mu \mathrm{m}$ and a length of $200 \mu \mathrm{m}$ of the transformed zone ahead of the crack tip. Yu and Shetty [43] reported a similar transformation zone shape. At the highest value for the fracture toughness (9.9 $\mathrm{MPa} \mathrm{m}^{-1 / 2}$ ), as measured by SENB, Yu and Shetty [43] found a zone width of $166 \mu \mathrm{m}$ and a zone length ahead of the crack tip of $1961 \mu \mathrm{m}$. It was reasoned that the transformed zone ahead of the crack is not effective in shielding the crack and will decrease rather than increase the fracture toughness. Although this effect is probably compensated by the huge width of the transformed zone around the crack, the fracture

TABLE IV Fracture toughness and bending strength of $\mathrm{Ce}-\mathrm{TZP}$, $\mathrm{Y}, \mathrm{Ce}-\mathrm{TZP}$ and $\mathrm{Y}, \mathrm{Ti}-\mathrm{TZP}$ ceramics fractured at various temperatures. All samples are nearly $100 \%$ tetragonal after fracture

\begin{tabular}{lrll}
\hline Sample & $T_{\mathrm{f}}\left({ }^{\circ} \mathrm{C}\right)$ & $K_{\mathrm{lo}}\left(\mathrm{MPam}^{-1 / 2}\right)$ & $\sigma_{\mathrm{f}}(\mathrm{MPa})$ \\
\hline ZY4Ce2 & 20 & $6.64 \pm 0.82$ & $730 \pm 84$ \\
ZY4Ce2 & 765 & $3.66 \pm 0.45$ & $223 \pm 54$ \\
ZY5Ti5 & 20 & $5.66 \pm 0.32$ & $647 \pm 74$ \\
ZY5Ti5 & 325 & - & $516 \pm 101$ \\
ZY5Ti5 & 775 & $3.39 \pm 0.33$ & $338 \pm 60$ \\
ZCe12 & 20 & $6.63 \pm 0.55$ & $231 \pm 34$ \\
\hline
\end{tabular}


toughness should be lower than what can be expected from transformation zone measurements. However this cannot account fully for the observed differences. Another effect might be found in the method of measurement. As Ce-TZP is known to show transformation plasticity $[44,45]$ no or only very small cracks are found during indentation of these materials which gives rise to a higher calculated value for the fracture toughness. Therefore indentation seems to overestimate the fracture toughness and thus not a very appropriate technique for Ce TZP materials. As Tsukuma [14] used indentation as a measuring technique this means that the actual fracture toughness value of the Ce-TZP material measured by him is probably much lower than the reported one.

\subsection{Transformability of the tetragonal phase}

When transformation toughening is the main toughening mechanism it is important, as mentioned before, to maximize the value of $V_{\mathrm{f}}(h)^{1 / 2}$. This requires a ceramic which transforms easily under the influence of an applied external stress (i.e. the stability of the tetragonal phase should be relatively low). This means that the $M_{\mathrm{s}}$ temperature should be just below room temperature. The $M_{\mathrm{s}}$ temperature is influenced by the grain size (increasing grain size decreases the stability) and the composition. According to Kim [46] and Yoshimura [47] the compositional effect is represented by the tetragonality ( $c / a$ ratio where $c$ and $a$ represent the unit cell axes of the tetragonal phase) of the tetragonal phase.

When using ceramics with similar grain size but different tetragonality Kim [46] showed that the $M_{\mathrm{s}}$ temperature increased (i.e. a less stable material) with increasing tetragonality. This was supported by the observation that the fracture toughness also increased with increasing tetragonality (the $M_{\mathrm{s}}$ temperature was still below room temperature).

Yoshimura [47] studied the effect of composition on the tetragonality in the $\mathrm{ZrO}_{2}-R \mathrm{O}_{1.5}$ system with $R=\mathrm{Nd}, \mathrm{Sm}, \mathrm{Y}, \mathrm{Er}, \mathrm{Yb}$. He showed that the tetragonality essentially depends on the dopant content and not on the dopant species. Although the lattice parameters of the tetragonal phase varied systematically with the ionic radii of the species, their tetragonality remained the same. In addition to this Kim [46] also studied species other than trivalent species. $\mathrm{He}$ showed that the cation valence difference also influenced the stability of the tetragonal phase. In general the stability seemed to decrease with increasing cation valence (when using the same amount of dopant).

In Table $\mathrm{V}$ the tetragonalities of our samples are listed. As is evident our results are in good agreement with those of Yoshimura [47] and Kim [46] as the tetragonality decreases with increasing dopant concentration. Indeed, Wang et al. [8] found a higher fracture toughness for a ZY4 ceramic compared to a ZY6 ceramic when using ceramics with similar grain size. Comparing the tetragonalities of the $\mathrm{Y}-\mathrm{TZP}$ materials with those of the cerium containing materials (with the same dopant concentration, see Table V), it becomes clear that cerium (and especially titanium)
TABLE V Tetragonality of $\mathrm{Y}, \mathrm{Ce}$ and Ti doped zirconia ceramics

\begin{tabular}{ll}
\hline Sample & Tetragonality $(c / a)$ \\
\hline ZY4 & 1.0163 \\
ZY5 & 1.0150 \\
ZY5.8 & 1.0141 \\
ZCe6.8 & 1.0194 \\
ZCe9 & 1.0190 \\
ZCe12 & 1.0186 \\
ZY4Ce2 & 1.0159 \\
ZY4Ce4 & 1.0154 \\
ZY4Ce10 & 1.0146 \\
ZY5Ti5 & 1.0182 \\
\hline
\end{tabular}

are weaker stabilizers than yttrium. Therefore, with the same alloying content, larger grain sizes are required in the Y-TZP ceramics compared with the Ce-TZP, Y,Ce-TZP and Y,Ti-TZP ceramics to obtain a similar transformation or in an alternative formulation: smaller grain sizes are necessary in the latter three groups to inhibit the transformation when the same amount of dopant is used.

The stability of the tetragonal phase may also be influenced by the presence of a second tetragonal phase, which is called $t^{\prime}$-phase, within the microstructure. The existence of the $t^{\prime}$-phase has been demonstrated in recent studies on yttria-doped zirconia ceramics [47-50]. This $t^{\prime}$-phase is formed by a diffusionless transformation from the cubic phase by rapid cooling $[47,49]$ and is believed to be non-transformable [49]. This is an undesired property in obtaining a high fracture toughness. Amongst others, Yoshimura [47] supposed that this non-transformability can be attributed mainly to a $c / a$ ratio closer to unity than that of the transformable tetragonal phase with the same composition. This implies that this $t^{\prime}$-phase might be considered as a $t$-phase with apparent higher dopant concentration. The presence of the $t^{\prime}$-phase can be demonstrated using X-ray diffraction in the 20 range $72-75^{\circ}$ [50]. Due to extensive peak overlap and $K \alpha_{2}$ contributions the resolution is rather poor. Therefore the $t^{\prime}$-phase is only observed in the absence of the cubic $\{400\}$ reflections and with large amounts of $t^{\prime}$-phase. In our samples we did not detect a $t$-phase with different lattice parameters, besides, in most of our samples the sintering temperature was below the temperature where the cubic phase is present [47]. Therefore $t^{\prime}$-phase was probably not present in our samples.

\subsection{Mechanical properties of $Y-T Z P$ after HIPping}

Preliminary experiments were carried out on a ZY5 sample which was post-HIPped. After the HIP treatment the density increased to $98.5 \%$. At room temperature the bending strength was $634 \pm 80 \mathrm{MPa}$ $(m=18)$ and the fracture toughness 6.94 $\pm 0.43 \mathrm{MPa} \mathrm{m}^{-1 / 2}$ (no monoclinic phase detected on the fracture surface). Compared with the conventionally sintered Y-TZP materials (the grain size of the sample is expected to be between $0.2-0.3 \mu \mathrm{m}$ ) the bending 
strength and Weibull modulus increased, whereas the fracture toughness decreased slightly. The increased bending strength might be attributed to a (presumably) smaller critical flaw size. As the sample was still not completely dense a further improvement of the strength can be expected with decreasing porosity. The reason why the fracture toughness decreased is not yet clear.

\section{Conclusions}

A nano-crystalline powder with a grain size of $8 \mathrm{~nm}$ can be sintered pressureless to an almost dense ceramic $(97 \%)$ with a small grain size $(<0.3 \mu \mathrm{m})$. Despite the fact that no stress induced phase transformation is observed, the material with an average grain size of $0.18 \mu \mathrm{m}$ exhibited a bending strength of $440 \mathrm{MPa}$ at room temperature which decreased linearly to $300 \mathrm{MPa}$ at $750^{\circ} \mathrm{C}$. The fracture toughness dropped from $7.3 \mathrm{MPa} \mathrm{m}^{-1 / 2}$ at room temperature to $4.5 \mathrm{MPa} \mathrm{m}{ }^{-1 / 2}$ at $750^{\circ} \mathrm{C}$. For the ceramic with a grain size of $0.3 \mu \mathrm{m}$ bending strengths of 530 and $235 \mathrm{MPa}$ were obtained at 20 and $750^{\circ} \mathrm{C}$, respectively. The fracture toughness dropped from $8.4 \mathrm{MPa} \mathrm{m}^{-1 / 2}$ at room temperature to $4.3 \mathrm{MPam}^{-1 / 2}$ at $750^{\circ} \mathrm{C}$. Several observations point to crack deflection as a toughening mechanism. This is expected to lead to even higher bending strength and fracture toughness values at room as well as at high temperature, when ceramics with grain sizes smaller than $0.1 \mu \mathrm{m}$ are used and the density is further increased.

As expected the coarser grained Y-TZP ceramics (grain size about $0.75 \mu \mathrm{m}$ ) showed good fracture toughness $\left(8.3 \mathrm{MPam}^{-1 / 2}\right)$ and bending strength $(650 \mathrm{MPa})$ at room temperature which strongly decrease at higher temperatures (to $250 \mathrm{MPa}$ and $2.8 \mathrm{MPa} \mathrm{m}^{-1 / 2}$ for the bending strength and fracture toughness, respectively). This is attributed to a large contribution of stress induced transformation toughening to the total toughness. A high fracture toughness corresponds with a relatively large transformation zone.

The Ce and Ti doped Y-TZP ceramics show similar behaviour as the $\mathrm{Y}-\mathrm{TZP}$ ceramics. Also in this case a similar toughening mechanism might occur as in the Y-TZP ceramics.

The stability of the tetragonal phase increases with increasing dopant content. From the tetragonalities of the tetragonal phase it could be demonstrated that cerium and titanium are weaker stabilizers for the tetragonal phase than yttrium.

Probably no fracture toughness decreasing $t^{\prime}$-phase was present in our ceramics.

\section{Acknowledgements}

We thank Professor N. Claussen (Technische Universität Hamburg-Harburg) for performing the HIP experiments. This research was partly supported by the Innovative Research Program on Technical Ceramics (IOP-TK) with financial aid of the Dutch Ministry of Economic Affairs.

\section{References}

1. F. F. LANGE, J. Mater. Sci. 17 (1982) 240.

2. K. TSUK UMA and K. UEDA, J. Amer. Ceram. Soc. 68 (1985) C-56.

3. T. MASAKI and K. SINJO, Ceram. Int. 13 (1987) 109

4. A. P. DRUSCHITZ and J. G. SCHROTH, J. Amer. Ceram. Soc. 72 (1989) 1591.

5. P. J. WHALEN, F. REIDINGER and R. F. ANTRIM, ibid. 72 (1989) 319.

6. K. HABERKO and R. PAMPUCH, Ceram. Int. 9 (1983) 8.

7. P. DURAN, P. RECIO, J. R, JURADO, C. PASCUAL, F. CAPEL and C. MOURE, J, Mater. Sci. 24 (1989) 708.

8. J. WANG, M. RAINFORTH and R. STEVENS, $J, B r$. Ceram. Trans. 88 (1989) 1.

9. H. Y. LU and S. Y. CHEN, J. Amer. Ceram. Soc. 70 (1987) 537.

10. T. SATO, S. OHTAKI, T. ENDO and M. SHIMADA, Int. J. High. Techn. Ceram. 2 (1986) 167.

11. A. G. EVANS, Mater. Sci. Eng. A105/106 (1988) 65

12. F. F. LANGE, J. Mater. Sci. 17 (1982) 235.

13. R. M. Mc M EEKING and A. G. EVANS, J. Amer. Ceram. Soc. 65 (1982) 242

14. K. TSUKUMA, Amer. Ceram. Soc. Bull. 65 (1986) 1386

15. F. F. LANGE, J. Mater. Sci. 17 (1982) 235.

16. D. MICHEL, L. MAZEROLLES and M. PEREZ y YORBA, J. Mater. Sci. 18 (1983) 2618

17. R. P. INGEL, D. LEWIS, B. A. BENDER and R. W. RICE, J. Amer. Ceram. Soc. 65 (1982) C-150.

18. J. S. BOUMA, G. S. A. M. THEUNISSEN, A. J. A. WINNUBST and A. J. BURGGRAAF, in Materials Science Monographs Vol. 68, Ceramics Today-Tomorrow's Ceramics, edited by P. Vincenzini (Elsevier Science Publishers, London, 1991) pp. 1601-1611.

19. A. J. A. WINNUBST and A. J. BURGGRAAF, in "Advances in Ceramics, Vol. 24A: Science and Technology of Zirconia III", edited by S. Somiya, N. Yamamoto and H. Yanagida (The American Ceramic Society, Ohio, 1988) p. 39.

20. G. S. A. M. THEUNISSEN, A. J. A. WINNUBST and A. J. BURGGRAAF, J. Eur. Ceram. Soc, in press.

21. J.-G. DUH, H.-S. DAI and B.-S. CHIOU, ibid. 71 (1988) 813.

22. B. BASTIDE, P. CANALE and P. ODIER, J. Eur. Ceram. Soc. 5 (1989) 289.

23. T. SATO, T. FUKISHIMA, T. ENDO and M. SHIMADA, in "Science of Ceramies 14", edited by D. Taylor (The Institute of Ceramics, UK, 1988) p. 1407.

24. W. F. M. GROOT ZEVERT, A. J. A. WINNUBST, G. S. A M. THEUNISSEN and A. I. BURGGRAAF, J. Mater. Sci. 25 (1990) 3449

25. H. J. OEL, Ber. Dtsch. Keram. Ges. 43 (1966) 624.

26. J. D. SULLIVAN and P. H. LAUZON, J, Mater. Sci. Lett. 5 (1986) 1245

27. G. de WITH, ibid. 16 (1981) 1702.

28. V. G. KERAMIDAS and W. B. WHITE, J. Amer. Ceram. Soc. 57 (1974) 22.

29. M. ISHIGAME and T. SAKURAI, ibid. 60 (1977) 367.

30. D. R. CLARKE and F. ADAR, ibid. 65 (1982) 284.

31. A. J.A. WINNUBST, K. KEIZER and A. J. BURGGRAAF, J. Mater. Sci. 18 (1983) 1958.

32. A. V. VIRKAR and R. L. K. MATSUMOTO, J. Amer. Ceram. Soc. 69 (1986) C-224.

33. G. V. SRINIVASAN, J.-F, JUE, S.-Y. KUO and A. V. VIRKAR, ibid. 72 (1989) 2098.

34. B.-S. LI, J.-S. CHERNG, K. J. BOWMAN and I.-W. CHEN, ibid. 71 (1988) C-362.

35. F. REIDINGER and P. J. WHALEN, Mater. Res. Soc. Symp. Proc. 78 (1987) 25.

36. K. T. FABER and A. G. EVANS, Acta Metall. 31 (1983) 577.

37. K.-H. HEUSSNER and N. CLAUSSEN, J. Eur. Ceram. Soc. 5 (1989) 193.

38. K. T. FABER and A. G. EVANS, Acta Metall. 31 (1983) 565.

39. A. J. BURGGRAAF, K. KEIZER and B. A. van HASSEL, in "Surfaces and interfaces of ceramic materials", edited by L.-C. Dufour et al. (Kluwer Academic Publishers, Deventer, 1989) p. 705 .

40. G. S. A. M. THEUNISSEN, PhD Thesis, University of Twente, The Netherlands (1991) 
41. G. S. A. M. THEUNiSSEN, A. J. A. WINNUBST and A. J. BURGGRAAF, J. Eur. Ceram. Soc., in press.

42. L. R. F. ROSE and M. V. SWAIN, Acta Metall. 36 (1988) 955.

43. C.-Y. Y U and D. K. ShET TY, J. Amer. Ceram. Soc. 72 (1989) 921.

44. P. E. REYES-MOREL and I-W. CHEN, ibid. 71 (1988) 343.

45. R. H. J. HANNINK and M. V. SWAIN, ibid. 72 (1989) 90.

46. D.-J. KIM, ibid. 73 (1990) 115.

47. M. YoShimuRA, Bull. Amer. Ceram. Soc. 67 (1988) 1950.

48. C. A. ANDERSSON and T. K. GUPTA, in "Advances in Ceramics, Vol. 3: Science and Technology of Zirconia I", edited by A. H. Heuer and L. W. Hobbs (The American Ceramic Society, Ohio, 1981) p. 184.

49. V. LANTERI, A. H. HEUER and T. E. MITCHELL, in "Advances in Ceramics, Vol. 12, Science and Technology of Zirconia II", edited by N. Claussen, M. Rühle and A. H. Heuer (The American Ceramic Society, Ohio, 1984) p. 118.

50. C. A. LEACH, J. Mater. Sci. Lett. 6 (1987) 303.

Received 22 April

and accepted 5 August 1991 